\title{
Intravenous acetaminophen: A study of effectiveness of practice of intraoperative administration in children undergoing adenotonsillectomy
}

Kesavan Sadacharam* and Bruce Randall Brenn

*Correspondence: kesavan654@gmail.com

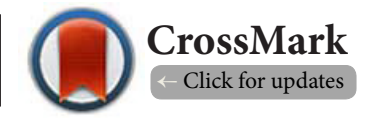

Nemours Alfred I duPont Hospital for Children, 1600 Rockland Road, Wilmington DE 19899, USA.

\begin{abstract}
Purpose: Adenotonsillectomyis one of the most common procedures performed in children. Perioperative pain management in this surgical population is challenging due to obstructive sleep apnea and other comorbidities. As a result, multimodal analgesia is increasingly advocated. Acetaminophen and nonsteroidal anti- inflammatory drugs are the most popular drugs used as part of multimodal analgesia. The purpose of this study is to examine the impact of intraoperative administration of intravenous acetaminophen on opioid use pattern during the perioperative period in children undergoing adenotonsillectomy.
\end{abstract}

Methods: This is a retrospective study of prospectively collected data from electronic medical records. We reviewed the patient demographics, morphine use during the intraoperative and immediate postoperative period, pain scores, and need for rescue analgesics in the post-anesthesia care unit (PACU). The dose of Intravenous Acetaminophen used in the study was $15 \mathrm{mg} / \mathrm{kg}$. Acetaminophen was administered by infusion over a period of 15 minutes. Case control matching between the morphine-only and intravenous acetaminophen groups was performed before analysis.

Results: After matching, we had 91 patients in both the morphine-only and intravenous acetaminophen groups. The intravenous acetaminophen group received significantly less morphine during the intraoperative period. However, this same group needed significantly more morphine in the PACU.

Interestingly at the time of discharge, there was no difference in the total amount of morphine used between two groups. In addition, there was no significant difference in pain scores between the groups.

Conclusion: Intraoperative administration of Intravenous acetaminophen does not decrease the amount of morphine used during the immediate perioperative period in children undergoing adenotonsillectomy. Our results question the usefulness of timing of administration of intravenous acetaminophen as a part of multimodal analgesia in our surgical population.

Keywords: Intraoperative pain management, post operative pain management, intravenous acetaminophen, multimodal analgesia, adenotonsillectomy

\section{Introduction}

The most common indication for adenotonsillectomy in children is obstructive sleep apnea (OSA) or sleep disordered breathing [1]. Postoperative pain, nausea, and vomiting are the most common problems in the postoperative period. Frequently, children with OSA have other comorbidities, including obesity, which add to the management challenges in the perioperative period.

Traditionally, opioids have been the mainstay of pain man- agement for adenotonsillectomy, intra- and postoperatively. Recently, awareness has increased about the harmful effects associated with opioid-based pain management [2-4]. It is well known that patients with OSA have altered sensitivity to opioid administration [3] leading to increased risk of apnea and respiratory depression and poor outcomes [5]. To prevent the side effects associated with opioids, multimodal analgesia is advocated [6]. The well-known regimen used to provide 
Sadacharam et al. Journal of Anesthesiology \& Clinical Science 2018,

multimodal analgesia in this patient population is infiltration of the tonsil bed with local anesthetics, nonsteroidal anti-inflammatory drugs, and acetaminophen.

Acetaminophen is administered by either the oral, rectal, or intravenous (IV) route. Since 2011, IV acetaminophen is Food and Drug Administration-approved for use in children older than 2 years of age. Since then, it has gained popularity for perioperative pain management here in the USA [7]. However, the evidence for superiority of IV acetaminophen over other routes of administration immediately after surgery is not well established, especially for pediatric adenotonsillectomies. Furthermore, use of IV acetaminophen is not without its drawbacks, which include potential accidental overdose and its high cost compared with other routes of administration.

The objective of this study was to examine the impact of intraoperative administration of IV acetaminophen on the opioid use pattern during the intraoperative and immediate postoperative period in children undergoing adenotonsillectomy in a tertiary care children's hospital.

\section{Methods}

After obtaining approval from our facility's Institutional Review Board, the anesthetic records of all children who had adenotonsillectomy during a six-month period between April and October 2016, in a tertiary care children's hospital in the Mid-Atlantic (USA), were examined. It is a retrospective study. All patients who had adenotonsillectomy during the above-mentioned period were identified from our hospital's electronic medical records (Epic, Verona WI USA), and data were extracted from our prospectively collected anesthesia module, Epic Anesthesia.

The inclusion criteria for the study were children younger than 10 years of age who had adenotonsillectomy and morphine only as the opioid in the perioperative period. The exclusion criteria include children with weight over 50 kilograms, use of dexmedetomidine during the perioperative period, use of narcotics other than morphine during the perioperative period, American Society of Anesthesiologists (ASA) class III and IV, total tonsillectomy, and ear tube placement along with adenotonsillectomy.

All patients were premedicated with intranasal or oral midazolam with dose standardized as per weight (put in dosages). The standard dose of intranasal and oral midazolam in our practice were $0.2 \mathrm{mg} / \mathrm{kg}$ and $0.5 \mathrm{mg} / \mathrm{kg}$ respectively and it is administered 30 minutes before the start of procedure. Anesthetic induction was achieved with a combination of oxygen, nitrous oxide, and sevoflurane and was maintained with sevoflurane, oxygen, and air. All patients received dexamethasone at the dose of $0.5 \mathrm{mg} / \mathrm{kg}$ to the maximum of 10 $\mathrm{mg}$ and ondansetron $0.1 \mathrm{mg} / \mathrm{kg}$ as prophylaxis for nausea and vomiting at the time of induction. During the intraoperative period, administration of morphine was at the discretion of the anesthesiologist. Postoperatively, morphine, ketorolac, and oral acetaminophen were used for breakthrough pain. As per hospital protocol, the criteria for overnight hospital stay after this surgery is age younger than 3 years, severe clinical or sleep study diagnosed sleep apnea, and/or any intra- or postoperative complication. Patients who planned to go home after the surgery were discharged after 120 minutes only if they met the discharge criteria prescribed by the postanesthesia care unit (PACU).

Based on medical record review, the patients were divided into two groups depending on whether they received IV acetaminophen intraoperatively or not. The dose of Acetaminophen is standardized in our practice as $15 \mathrm{mg} / \mathrm{kg}$. Acetaminophen was administered by infusion over a period of 15 minutes. Continuous variables such as age, weight, total intraoperative morphine received, total postoperative morphine received, number of rescue doses of morphine, maximum pain score recorded in the PACU, and time to discharge were recorded. Nominal data such as gender, the presence or absence of OSA, and the presence or absence of postoperative complications were collected. Ordinal data included ASA status. Derived data, such as the total morphine received during the encounter and morphine received per kilogram, were calculated and recorded.

Case control matching estimating common odds ratio utilizing the Mantel-Haenszel test was achieved using age, weight, gender, and presence of OSA as covariates. Student's t-test was used for continuous variables with significance at $95 \%$ confidence interval (CI). IBM SPSS Statistics 22.0 software was used to analyze the data.

\section{Results}

Figure 1 shows a consort diagram illustrating the selection of patients. Case control matching yielded 91 patients in each group. By design, there was no difference between the groups in terms of age, weight, gender, and incidence of OSA.

The IV acetaminophen group received significantly less intraoperative morphine $(1.64 \pm 0.73 \mathrm{mg}: 95 \% \mathrm{Cl}, 1.48-1.79$, $P$ Value 0.01) compared with the control group (1.91 \pm 0.69 mg: 95\%Cl,1.77-2.06) (Table 1). The IV acetaminophen group also received less intraoperative morphine per kilogram $(0.08 \pm 0.02 \mathrm{mg} / \mathrm{kg}: 95 \% \mathrm{Cl}, 0.08-0.09)$ versus the control group $(0.10 \pm 0.02 \mathrm{mg} / \mathrm{kg}: 95 \%, 0.09-0.10$ P Value 0.00$)$ (Table 1). However, the IV acetaminophen group received more morphine per kilogram in the PACU $(0.04 \pm 0.03 \mathrm{mg} / \mathrm{kg}: 95 \% \mathrm{Cl}, 0.03-0.05)$ versus the morphine-only group $(0.03 \pm 0.03 \mathrm{mg} / \mathrm{kg}: 95 \%$ $\mathrm{Cl}, 0.02-0.04$, P Value 0.03) (Table 1). Neither the total morphine nor the total morphine per kilogram received in the operating room and the PACU combined was statistically different.

The percentage of patients receiving rescue doses of opioid in the PACU; the maximum faces, legs, activity, cry, consolability (FLACC) pain scores recorded; and the time to discharge was not statistically significant between the two groups (Table 2).

\section{Discussion}

The goal of administration of IV acetaminophen as a part of 


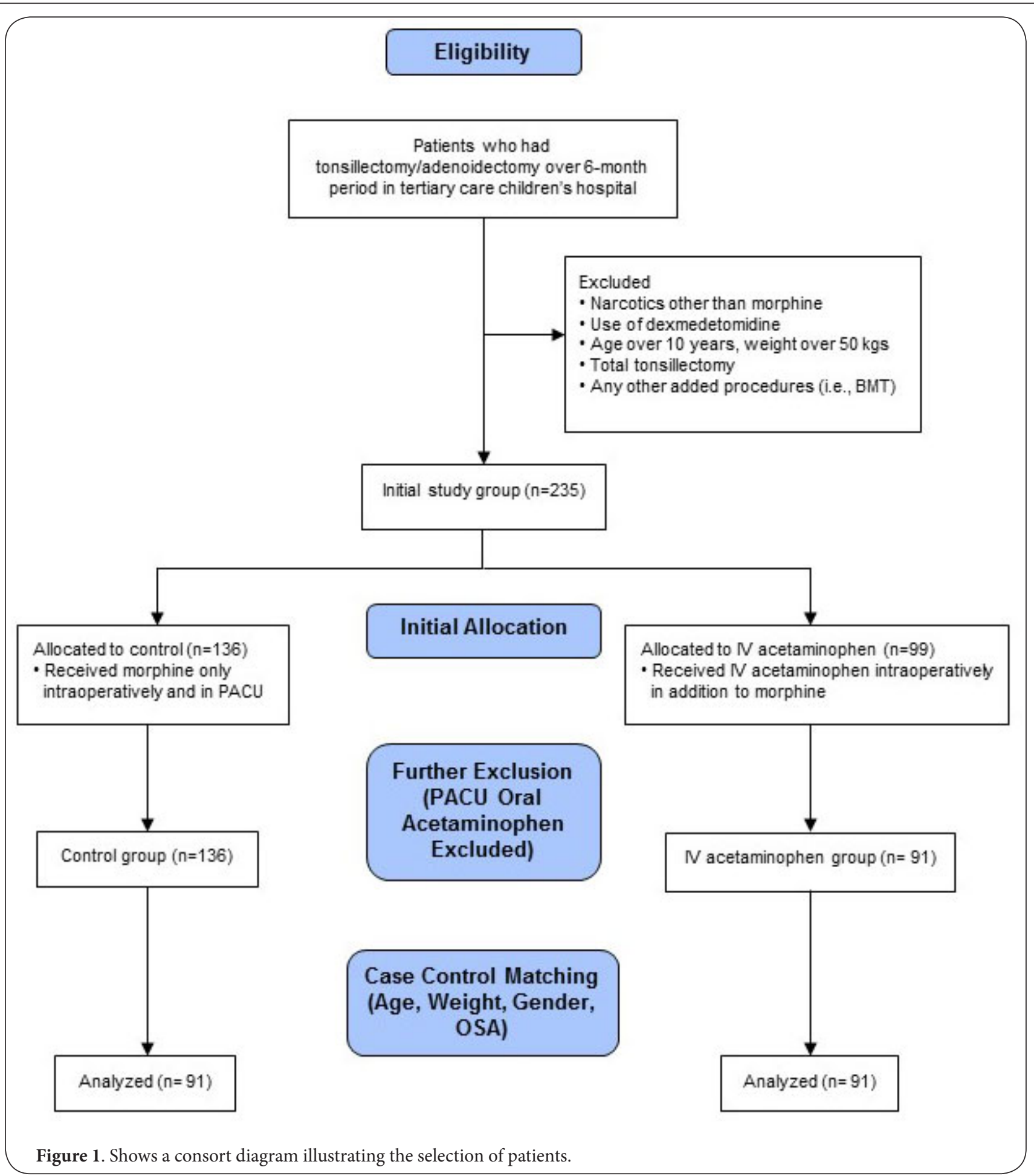

multimodal analgesia is to decrease the amount of opioid administered during the immediate perioperative period in a patient population with the significant problem of OSA. In this environmental retrospective case control analysis, there was no decrease in morphine administration overall. While there appeared to be a conscious effort to reduce morphine administration intraoperatively, the morphine given in the
PACU made up for this lack resulting in no difference in total morphine administration. Additionally, administration of intraoperative IV acetaminophen decreased neither the pain scores nor the length of stay in the recovery room. As a result, we speculate that administration of IV acetaminophenin the post-operative period for breakthrough pain may be a better practice than intraoperative administration. 
Table 1. (Primary Outcome Measures - Morphine consumption during the surgery, in the PACU and total morphine administered at the time of discharge between two groups).

\begin{tabular}{lccc}
\hline & Control Group & IV Acetaminophen Group & $P$ value \\
\hline Intraop morphine & $1.91 \pm 0.69(1.77-2.06)$ & $1.64 \pm 0.73(1.48-1.79)$ & 0.0100 \\
PACU morphine & $0.63 \pm 0.74(0.48-0.79)$ & $0.77 \pm 0.69(0.62-0.91)$ & 0.2070 \\
& $2.45 \pm 1.02(2.22-2.67)$ & $2.41 \pm 1.02(2.22-2.67)$ & 0.8350 \\
Total morphine & $0.098 \pm 0.028(0.092-0.104)$ & $0.081 \pm 0.026(0.076-0.087)$ & 0.0000 \\
Intraop morphine per kg & & & \\
PACU morphine per kg & $0.031 \pm 0.032(0.024-0.037)$ & $0.041 \pm 0.037(0.024-0.037)$ & 0.0390 \\
$\begin{array}{l}\text { Total morphine per kg } \\
\text { \% Receiving rescue doses }\end{array}$ & $0.125 \pm 0.042(0.116-0.133)$ & $0.123 \pm 0.045(0.113-0.132)$ & 0.7680 \\
\hline
\end{tabular}

Data presented as mean \pm standard deviation (95\% confidence limits)

IV intravenous, PACU post-anesthesia care unit, Dose of Intravenous Acetaminophen used is $15 \mathrm{mg} / \mathrm{kg}$.

Table 2. (Secondary outcome measures - Comparison of pain scores, time to discharge from PACU and percentage of patients received rescue doses of Morphine between two groups).

\begin{tabular}{lccc}
\hline & $\begin{array}{c}\text { Control Group } \\
(\mathbf{n = 9 1 )}\end{array}$ & $\begin{array}{c}\text { IV Acetaminophen } \\
\text { Group (n=91) }\end{array}$ & P value \\
\hline \% Receiving rescue opioid doses & $62 \%$ & $75 \%$ & 0.0800 \\
Max PACU FLACC pain score & $4.51 \pm 3.14(3.85-5.15)$ & $4.93 \pm 3.15(4.27-5.59)$ & 0.3610 \\
Time to discharge (min) & $109 \pm 40(101-118)$ & $117 \pm 43(108-126)$ & 0.2150 \\
\hline
\end{tabular}

Data presented as mean \pm standard deviation (95\% confidence limits).

IV intravenous, PACU post-anesthesia care unit, FLACC faces, legs, activity, cry, consolability scale.

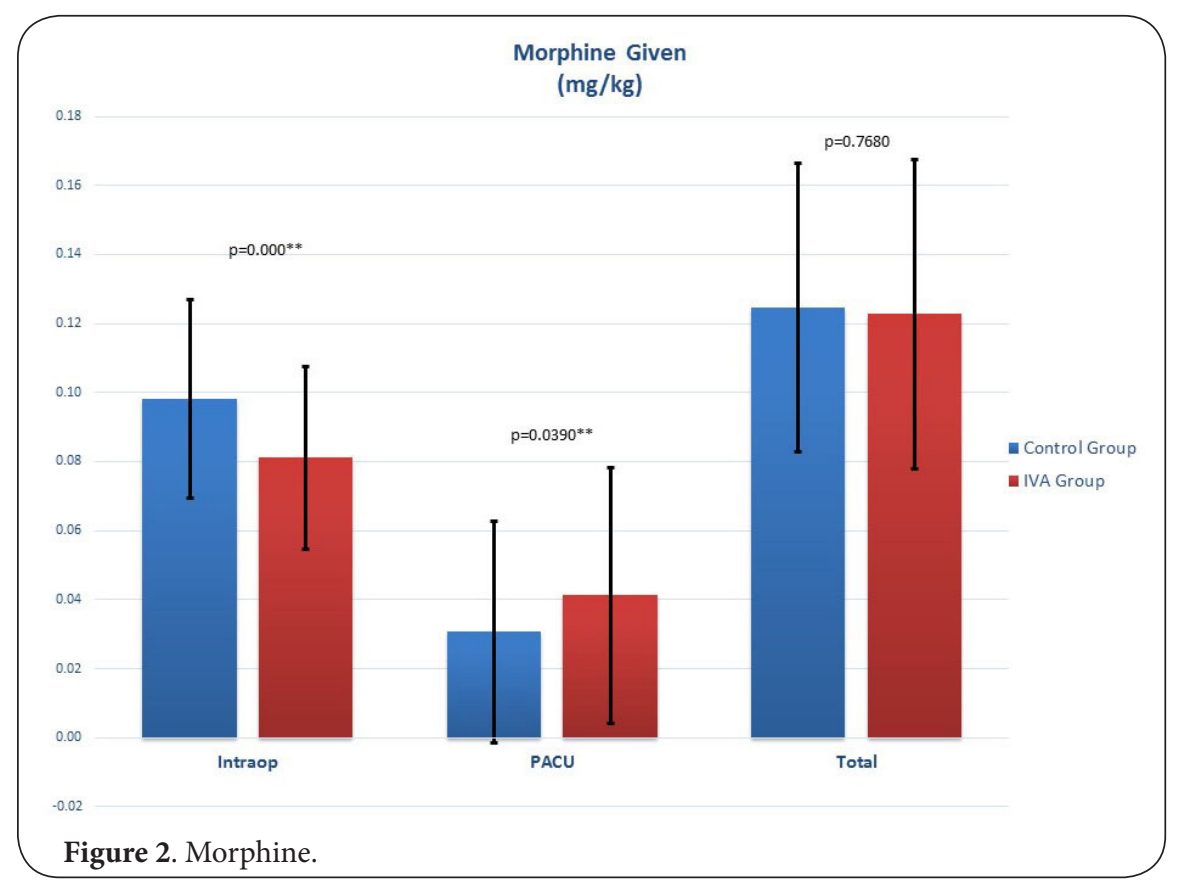


Traditionally during the perioperative period, acetaminophen is administered either by the rectal or oral route. The advantages of enteral acetaminophen are easy availability, safety, and cost effectiveness. However, the clinical effectiveness of this therapy as a part of multimodal analgesia during the perioperative period is inconclusive $[\mathbf{8 , 9}]$. Enteral acetaminophen has questionable potency, inconsistent absorption from the gastrointestinal tract, and a lack of evidence for optimal dose of administration [10]. Preoperative administration of oral acetaminophen raises a concern about exceeding safe gastric volume and of provoking anxiety in parents and children before the surgery [11]. Rectal acetaminophen has long been known to have poor and unpredictable absorption. In addition, rectal acetaminophen is inconvenient to administer in the operating room during fast-paced surgery such as ear tube placement and is not well accepted in older children and adults.

The introduction of IV acetaminophen has addressed some of the previously mentioned problems associated with the oral or rectal route. Compared with other routes, administration by the IV route allows effective peak plasma levels to be achieved consistently and rapidly during the surgery [12]. In addition, the dose of IV acetaminophenin children over the age of 2 years is uniform, and the current dosing regimen provides effective plasma concentration [12]. However, the evidence is inconclusive regarding the opioid sparing effectiveness of preoperative or intraoperative administration of IV acetaminophen compared with other routes in children who undergo adenotonsillectomy [13]. Moreover, the cost of IV acetaminophen is significantly higher than rectal or oral acetaminophen, and the potential for serious adverse events due to medication dosing errors raises concern among hospital management about its cost effectiveness and patient safety $[14,15]$.

In our study, we compared the effectiveness of multimodal analgesia with the use of intraoperative IV acetaminophen and opioid-based management for perioperative pain control during adenotonsillectomy. We found no significant difference in the total opioid use between the morphine-only control and IV acetaminophen group at the time of discharge from the PACU. The patients in the acetaminophen group received significantly less morphine in the intraoperative period. We speculate that anesthesiologists may have administered less morphine in the IV acetaminophen group reasoning that IV acetaminophen will decrease opioid requirement in the recovery room. However, our finding that the IV acetaminophen group needed significantly more morphine in the PACU compared with the control group does not support this speculation. At the time of discharge, our data show that both the control and the IV acetaminophen groups received the same amount of morphine. We also recorded maximum pain scores in the PACU. Our PACU used the FLACC scale or numeric pain score depending on the age of the patient. Pain score was measured by the PACU nurses immediately after the recovery of consciousness and at various times at the discretion of the nurses. There were no statistically significant differences in maximum pain scores between the two groups.

Obstructive sleep apnea is a frequent indication of adenotonsillectomy in children, and multimodal analgesia increasingly is recommended to reduce opioid-related side effects such as respiratory depression and hypoxia in the immediate postoperative period. Since intraoperative administration of IV acetaminophen did not reduce opioid consumption, we speculate that it may be used in the PACU for breakthrough pain instead of Morphine. In addition, more research exploring other drugs to consider as part of multimodal analgesia in children who undergo adenotonsillectomy is necessary. Drugs such as ketamine and dexmedetomidine recently have been used for adenotonsillectomy in children; however, for use in routine practice, more research about dosing and effectiveness is needed.

Our study has some limitations. While controlled studies have shown the opioid sparing nature of nonsteroidal antiinflammatory drugs and IV acetaminophen, we failed to see this effect in an uncontrolled natural situation. We used a case control analysis to standardize the groups to the best of our ability. Still, our model is a retrospective review of prospectively collected data; therefore, one cannot assume causality, but only association. This method also runs the risk of incomplete data, which was a secondary reason to perform the case control analysis. In addition, the use of opioids in the operating room and the PACU was not controlled and was therefore at the discretion of the anesthesiologists and recovery room nurses.

\section{Conclusion}

Our six-month review showed there was no significant difference in the overall amount of opioid administered or pain scores between the morphine-only control and intraoperative IV acetaminophen groups. We speculate that intravenous acetaminophen may be more effective when used in the post anesthesia recovery room for breakthrough pain instead of Morphine to reduce the amount of opioid administered in this patient population.

\section{Competing interests}

The authors declare that they have no competing interests.

\section{Authors' contributions}

\begin{tabular}{|l|c|c|}
\hline Authors' contributions & KS & BRB \\
\hline Research concept and design & $\checkmark$ & $\checkmark$ \\
\hline Collection and/or assembly of data & $\checkmark$ & $\checkmark$ \\
\hline Data analysis and interpretation & $\checkmark$ & $\checkmark$ \\
\hline Writing the article & $\checkmark$ & $\checkmark$ \\
\hline Critical revision of the article & $\checkmark$ & $\checkmark$ \\
\hline Final approval of article & $\checkmark$ & $\checkmark$ \\
\hline Statistical analysis & $\checkmark$ & $\checkmark$ \\
\hline
\end{tabular}


Sadacharam et al. Journal of Anesthesiology \& Clinical Science 2018, http://www.hoajonline.com/journals/pdf/2049-9752-7-1.pdf

\section{Acknowledgement}

We acknowledge Zhaoping He for her help with the statistical analysis.

Publication history

EIC: D. John Doyle, Case Western Reserve University, USA.

Received: 04-Jan-2018 Final Revised: 10-Feb-2018

Accepted: 16-Mar-2018 Published: 24-Mar-2018

\section{References}

1. Erickson BK, Larson DR, St Sauver JL, Meverden RA and Orvidas LJ. Changes in incidence and indications of tonsillectomy and adenotonsillectomy, 1970-2005. Otolaryngol Head Neck Surg. 2009; 140:894-901. | Article | PubMed

2. Subramanyam R, Chidambaran V, Ding L, Myer CM, 3rd and Sadhasivam S. Anesthesia- and opioids-related malpractice claims following tonsillectomy in USA: LexisNexis claims database 1984-2012. Paediatr Anaesth 2014; 24:412-20. | Article | PubMed

3. Brown KA, Laferriere A and Moss IR. Recurrent hypoxemia in young children with obstructive sleep apnea is associated with reduced opioid requirement for analgesia. Anesthesiology. 2004; 100:806-10. | Article | PubMed

4. Leong AC and Davis JP. Morbidity after adenotonsillectomy for paediatric obstructive sleep apnoea syndrome: waking up to a pragmatic approach. J Laryngol Otol. 2007; 121:809-17. | Article | PubMed

5. Cote CJ, Posner KL and Domino KB. Death or neurologic injury after tonsillectomy in children with a focus on obstructive sleep apnea: houston, we have a problem! Anesth Analg. 2014; 118:1276-83. | Article | PubMed

6. Patino $M$, Sadhasivam $S$ and Mahmoud $M$. Obstructive sleep apnoea in children: perioperative considerations. Br J Anaesth. 2013; 111 Suppl 1:i83-95. | Article I PubMed

7. Smith Smith HS. Perioperative intravenous acetaminophen and NSAIDs Pain Med. 2011; 12:961-81. | Article | PubMed

8. Wong I, St John-Green C and Walker SM. Opioid-sparing effects of perioperative paracetamol and nonsteroidal anti-inflammatory drugs (NSAIDs) in children. Paediatr Anaesth. 2013; 23:475-95. | Article | PubMed Abstract I PubMed FullText

9. Roberts CA, Shah-Becker S, Derr JB, Sedeek K and Carr MM. Effect of single dose intraoperative IV acetaminophen in pediatric tonsillectomy or adenotonsillectomy. Egyptian J Anaesth. 2017; 33:97-101.

10. Bremerich DH, Neidhart G, Heimann K, Kessler P and Behne M. Prophylactically-administered rectal acetaminophen does not reduce postoperative opioid requirements in infants and small children undergoing elective cleft palate repair. Anesth Analg. 2001; 92:907-12. | Article | PubMed

11. Engelhardt $T$ and Webster NR. Pulmonary aspiration of gastric contents in anaesthesia. Br J Anaesth. 1999; 83:453-60. | Pdf | PubMed

12. van der Westhuizen J, Kuo PY, Reed PW and Holder K. Randomised controlled trial comparing oral and intravenous paracetamol (acetaminophen) plasma levels when given as preoperative analgesia. Anaesth Intensive Care. 2011; 39:242-6. | Article | PubMed

13. Khobrani MA, Camamo JM and Patanwala AE. Effect of Intravenous Acetaminophen on Post-Anesthesia Care Unit Length of Stay, Opioid Consumption, Pain, and Analgesic Drug Costs After Ambulatory Surgery. P T. 2017; 42:125-139. | PubMed Abstract | PubMed FullText

14. Dart RC and Rumack BH. Intravenous acetaminophen in the United States: iatrogenic dosing errors. Pediatrics. 2012; 129:349-53. | Article I PubMed

15. Nevin DG and Shung J. Intravenous paracetamol overdose in a preterm infant during anesthesia. Paediatr Anaesth. 2010; 20:105-7. | Article | PubMed

\section{Citation:}

Sadacharam K and Brenn BR. Intravenous acetaminophen: A study of effectiveness of practice of intraoperative administration in children undergoing adenotonsillectomy. J Anesthesiol Clin Sci. 2018; 7:1. http://dx.doi.org/10.7243/2049-9752-7-1 